\title{
Examining the Effect of Radiant Exposure on Commercial Photopolimerizable Dental Resin Composites
}

\author{
Carlos Enrique Cuevas-Suárez ${ }^{1}$ (D), Belinda Pimentel-García ${ }^{1}$, Alejandro Rivera-Gonzaga ${ }^{1}$, \\ Carlos Álvarez-Gayosso ${ }^{2}$, Adriana Leticia Ancona-Meza ${ }^{1}$, Guillermo Grazioli ${ }^{3}$ \\ and Eliezer Zamarripa-Calderón 1,*
}

1 Academic Area of Dentistry, Health Sciences Institute, Autonomous University of the Hidalgo State, Circuito Ex Hacienda La Concepción Km. 1.5. San Agustín Tlaxiaca, Hidalgo, C.P. 42160, Mexico; cecuevas@uaeh.edu.mx (C.E.C.-S.); piq03594@uaeh.edu.mx (B.P.-G.); jose_rivera10098@uaeh.edu.mx (A.R.-G.); ancona@uaeh.edu.mx (A.L.A.-M.)

2 Faculty of Dentistry, National Autonomous University of México, Circuito de la Investigación Científica, Ciudad Universitaria, Delegación Coyoacán, Ciudad de México, C.P. 04510, Mexico; calvarezgayosso@comunidad.unam.mx

3 Department of Dental Materials, Faculty of Dentistry, University of the Republic, General Las Heras 1925, Montevideo, C.P. 11600, Uruguay; ggrazioli@odon.edu.uy

* Correspondence: eliezerz@uaeh.edu.mx; Tel.: +521-771-71-72000

Received: 31 August 2018; Accepted: 4 October 2018; Published: 7 October 2018

\begin{abstract}
The objective of this study was to evaluate the effect of radiant exposure on the chemical and physical properties of four commercial dental resin composites. The four dental resin composites used were Kalore, Admira, Tetric N-Ceram Bulk Fill, and Filtek Z350 XT. The composites were subjected to three curing protocols: $1000 \mathrm{~mW} / \mathrm{cm}^{2}$ for $5 \mathrm{~s}, 1000 \mathrm{~mW} / \mathrm{cm}^{2}$ for $10 \mathrm{~s}$, and $400 \mathrm{~mW} / \mathrm{cm}^{2}$ for $25 \mathrm{~s}$. The flexural strength, elastic modulus, water sorption, water solubility, degree of conversion, and polymerization shrinkage were evaluated. The results were analyzed by means of ANOVA and Tukey tests. For Admira and Kalore, significant differences between light exposure protocols were observed for the elastic modulus ( $\mathrm{p}$ 0.001), which was higher when a higher amount of radiant exposure was used. For Filtek Z350, differences were only observed for the degree of conversion ( $p<0.001)$, and a higher amount of radiant exposure allowed us to obtain higher values. The Tetric $\mathrm{N}$-Ceram Bulk Fill analysis showed significant differences for the elastic modulus and water sorption ( $p<0.001$ ), and specimens that had been subject to a radiant exposure of $10 \mathrm{~J} / \mathrm{cm}^{2}$ showed a higher elastic modulus. In most cases, the physical and mechanical properties analyzed were not affected by different radiant exposure values. Other resin-based composite (RBC) characteristics seem to have a greater influence on material properties.
\end{abstract}

Keywords: composite resin; dental restoration; photopolymerization

\section{Introduction}

Due to their versatility and aesthetic advantages, photopolymerizable resin-based dental composites (RBCs) have been widely used in the restoration of dental caries or other tooth defects [1]. In order to achieve optimal material properties throughout the entire restoration, RBCs are placed using layering techniques [2]. The multi-increment technique is time-consuming, and there exists significant demand for a reduction in cure time to minimize the time it takes to complete the chairside procedure [3]. 
The photopolymerization efficiency of RBCs is influenced by several factors [4]. Among them, factors related to the photopolymerization unit have been widely studied; for example, with regard to light irradiance, the use of at least $400 \mathrm{~mW} / \mathrm{cm}^{2}$ has been recommended [5,6]. Another directly related factor is radiant exposure, which is the product of irradiance $\left(\mathrm{mW} / \mathrm{cm}^{2}\right)$ and exposure time $(\mathrm{s})$. Radiant exposure $\left(\mathrm{J} / \mathrm{cm}^{2}\right)$ has a direct relationship with the degree of conversion and other important mechanical properties of photopolymerizable RBCs $[7,8]$. The amount of radiant exposure required to adequately polymerize an increment of an RBC varies greatly, and there is still much confusion over which specific irradiance and time combination will provide optimal polymerization within a short clinical timeframe [3].

Based on the principle known as the "exposure reciprocity law", which describes a reciprocal relationship between irradiance and exposure time to achieve equivalent polymerization of RBCs [9], there exists a tendency among dentists and manufacturers to use or suggest a high-power illumination to reduce the curing time [4]. It has been demonstrated that many resins appear to follow exposure reciprocity with regard to the degree of conversion, elastic modulus, hardness, and cure depth [10-12]. However, the validity of this rule has been challenged by other studies $[13,14]$. The available evidence for the exposure reciprocity law is contradictory because research groups have studied different resins, ranges of irradiance, and radiant exposures to investigate this phenomenon.

Recently, new types of photopolymerizable RBCs have been introduced, including low stress and low shrinkage composites, ormocer-based composites, and bulk-fill composites. These types of materials include new monomer, filler, or photoinitiator technologies that have not been fully studied. The introduction of new or modified dental products into the market requires a guarantee that these materials have at least similar properties to other RBCs.

Little is known about the effect of radiant exposure on these new types of materials. Consequently, the aim of this work was to evaluate the effect of radiant exposure on the physical and chemical properties of four resin-based composites. The null hypothesis tested was that similar properties will be achieved when composites are exposed to the same amount of radiant exposure $\left(5\right.$ and $\left.10 \mathrm{~J} / \mathrm{cm}^{2}\right)$ at different irradiance and time levels.

\section{Materials and Methods}

In this study, four dental resin composites were used: a low-shrink, low-stress composite (Kalore $^{\mathrm{TM}}$, GC Corporation, Tokyo, Japan), an ormocer-based composite (Admira ${ }^{\circledR}$, Voco, Cuxhaven, Germany), a bulk-fill composite (Tetric ${ }^{\circledR} \mathrm{N}$-Ceram Bulk Fill, Ivoclar-Vivadent, Schaan, Liechtenstein), and a nanofilled composite (Filtek ${ }^{\mathrm{TM}}$ Z350 XT, 3M ESPE, St. Paul, MN, USA). Information on their manufacture is listed in Table 1.

Table 1. Information on the manufacture of the resin-based composites.

\begin{tabular}{|c|c|c|c|}
\hline Material & Organic Matrix * & Inorganic Filler * & $\begin{array}{c}\text { Filler Load } \\
\text { \%Weight (Volume) }\end{array}$ \\
\hline $\begin{array}{l}\text { Kalore }^{\mathrm{TM}} \text { (GC Corp., } \\
\text { Tokyo, Japan) }\end{array}$ & $\begin{array}{c}\text { UDMA, Urethane } \\
\text { DX-511, dimethacrylate } \\
\text { comonomers }\end{array}$ & $\begin{array}{l}\text { Fluoro-aluminium-silicate glass, } \\
\text { Prepolymerized filler, and Silicon } \\
\text { dioxide }\end{array}$ & $82(55)$ \\
\hline $\begin{array}{c}\text { Admira }^{\circledR} \text { (Voco, Cuxhaven, } \\
\text { Germany) }\end{array}$ & $\begin{array}{l}\text { Polisiloxane, aliphatic } \\
\text { and aromatic monomers }\end{array}$ & $\begin{array}{l}\text { Apatite-sulphate-phosphate and } \\
\text { inorganic glass particles }\end{array}$ & $78(56)$ \\
\hline $\begin{array}{l}\text { Tetric }{ }^{\circledR} \text { N-Ceram Bulk Fill } \\
\text { (Ivoclar-Vivadent, Schaan, } \\
\text { Liechtenstein) }\end{array}$ & Bis-GMA, DMA & $\begin{array}{l}\text { Barium-aluminium-silicate glass, } \\
\text { ytterbium fluoride, and spherical } \\
\text { mixed oxide }\end{array}$ & $79(60)$ \\
\hline $\begin{array}{c}\text { Filtek }^{\mathrm{TM}} \text { Z350 XT (3M } \\
\text { ESPE, St. Paul, MN, USA) }\end{array}$ & $\begin{array}{l}\text { Bis-GMA, UDMA, } \\
\text { TEGDMA, Bis-EMA, } \\
\text { PEGDMA. }\end{array}$ & $\begin{array}{l}\text { Silica, zirconia, and aggregated } \\
\text { zirconia/silica clusters }\end{array}$ & $72.5(63.3)$ \\
\hline
\end{tabular}

\footnotetext{
* Information provided by the manufacturer. UDMA, urethane dimethacrylate; Bis-EMA, bisphenol A-glycol dimethacrylate; Bis-GMA, bisphenol A-glycidyl dimethacrylate; TEGDMA, triethylene glycol dimethacrylate; Bis-EMA, ethoxylated bisphenol a dimethacrylate; PEGDMA, Poly(ethylene glycol) dimethacrylate.
} 


\subsection{Curing Protocols and Radiant Exposures}

Composites were cured with a commercial light-emitting diode (LED) photopolymerization unit (LED Bluephase 16i, Ivoclar Vivadent, Schaan, Liechtenstein). They were subjected to three radiant exposure levels: Group A $\left(1000 \mathrm{~mW} / \mathrm{cm}^{2}\right.$ for $\left.5 \mathrm{~s}\left(5 \mathrm{~J} / \mathrm{cm}^{2}\right)\right)$; Group B $\left(1000 \mathrm{~mW} / \mathrm{cm}^{2}\right.$ for $10 \mathrm{~s}$ $\left.\left(10 \mathrm{~J} / \mathrm{cm}^{2}\right)\right)$; and Group C $\left(400 \mathrm{~mW} / \mathrm{cm}^{2}\right.$ for $\left.25 \mathrm{~s}\left(10 \mathrm{~J} / \mathrm{cm}^{2}\right)\right)$. The intensity of light irradiation was monitored using a digital radiometer (Bluephase meter, Ivoclar, Vivadent).

\subsection{Degree of Conversion}

The degree of conversion of the composite materials was determined by infrared spectroscopy (Frontier, Perkin Elmer, Waltham, MA, USA). An infrared spectrum of the uncured and the cured samples was obtained. The measurement was made in real time using an attenuated total reflection (ATR) unit. For each spectrum, the height of the aliphatic $C=C$ peak absorption at $1638 \mathrm{~cm}^{-1}$ and the height of the $\mathrm{C}=\mathrm{O}$ vibration at $1710 \mathrm{~cm}^{-1}$ were determined. The degree of conversion was determined in accordance with the following equation:

$$
\text { Degree of conversion }(\%)=100\left[1-\frac{\left(\frac{\mathrm{A}_{1638}}{\mathrm{~A}_{1710}}\right) \text { polymer }}{\left(\frac{\mathrm{A}_{1638}}{\mathrm{~A}_{1710}}\right) \text { monomer }}\right]
$$

where $\mathrm{A}_{1638}$ is the maximum height of the absorption peak at $1638 \mathrm{~cm}^{-1}, \mathrm{~A}_{1710}$ is the maximum height of the absorption peak at $1710 \mathrm{~cm}^{-1}$, "polymer" refers to the cured specimen, and "monomer" refers to the uncured material.

\subsection{Flexural Properties}

The flexural strength of the materials was evaluated in accordance with the specifications provided by the ISO-4049 International Standard, while the elastic modulus was evaluated using the square section of the flexural mechanical properties [15,16]. Sixty bar-shaped specimens $(25 \mathrm{~mm} \times 2 \mathrm{~mm} \times$ $2 \mathrm{~mm}$ ) were prepared by placing the uncured samples into a stainless steel mold that was placed on a glass slide that was covered by a Mylar ${ }^{\circledR}$ strip. A second strip and a glass slide were used to cover the mold. The samples were irradiated on both sides by the overlapping technique using the curing protocol previously described. After the polymerization process was performed, irregularities were removed using abrasive paper, and specimen dimensions were measured using a digital caliper (Mod. CD-6"C Mitutoyo. Tokyo, Japan). After storage in distilled water at $37^{\circ} \mathrm{C}$ for $24 \mathrm{~h}$, the specimens were placed in a universal mechanical test machine (Instron 4465, Norwood, MA, USA). A three-point flexural test was performed with a $1 \mathrm{kN}$ load cell at a crosshead speed of $1.00 \mathrm{~mm} / \mathrm{min}$ until a fracture occurred. The flexural strength (FS) and elastic modulus (EM) were calculated (in $\mathrm{MPa}$ and GPa, respectively) using the following equations:

$$
\mathrm{FS}=\frac{3 \mathrm{Fl}}{2 \mathrm{bh}^{2}} ; \mathrm{EM}=\frac{\mathrm{F}_{1} 1^{3}}{4 \mathrm{bh}^{3} \mathrm{~d}}
$$

where $F_{1}$ represents the load $(\mathrm{N})$ exerted on the specimen on the linear portion of the load-curve deflection curve, $\mathrm{F}$ is the maximum load $(\mathrm{N})$ exerted on the specimen at the point fracture, 1 is the distance $(\mathrm{mm})$ between the supports, $\mathrm{h}$ is the height $(\mathrm{mm})$ of the specimen, $\mathrm{b}$ is the width $(\mathrm{mm})$ of the specimen, and $\mathrm{d}$ is the deflection corresponding to the load $\mathrm{F}_{1}$. 


\subsection{Water Sorption and Solubility}

The hydric behavior of the materials was evaluated according to the specifications that are described in the ISO International Standard No. 4049. Sixty cylindrical discs (15 mm in diameter and $1 \mathrm{~mm}$ in thickness) were prepared in a stainless steel mold and polymerized following the curing protocol previously described. The samples were transferred to a desiccator, and their mass was monitored until a constant mass was obtained $\left(\mathrm{m}_{1}\right.$; the loss in mass of each specimen was not more than $0.1 \mathrm{mg}$ in a $24-\mathrm{h}$ period). Then, the volume (V) of each specimen was calculated by measuring the thickness and diameter of the samples. The samples were immersed in distilled water at $37^{\circ} \mathrm{C}$ for 7 days, and, after that, they were weighted to obtain $\mathrm{m}_{2}$. Finally, the samples were again placed in a desiccator and were weighted until their mass was found to remain constant $\left(\mathrm{m}_{3}\right)$. The water sorption (WSP) and solubility (WSL) were calculated using the following equations:

$$
\mathrm{W}_{\mathrm{sp}}=\frac{\mathrm{m}_{2}-\mathrm{m}_{3}}{\mathrm{~V}} ; \mathrm{W}_{\mathrm{sl}}=\frac{\mathrm{m}_{1}-\mathrm{m}_{3}}{\mathrm{~V}}
$$

\subsection{Polymerization Shrinkage}

The polymerization shrinkage (PS) was calculated using a linear transducer [17,18]. Disk-shaped specimens were prepared by placing the uncured composite $(0.17 \pm 0.04 \mathrm{~g})$ at the center of a square cross-section brass ring (internal diameter $16 \mathrm{~mm}$, height $1.24 \mathrm{~mm}$ ), which was adhesively bonded to a glass microscope slide. The disk specimen was then covered with a glass microscope cover-slip. Then, the armature of a displacement transducer was carefully positioned to be in contact with the center of the cover-slip. Samples were photopolymerized according to the protocol described in Section 2.1. The cover-slip deflects when shrinkage occurs, so the deflection at the center of the cover-slip was monitored over time by the transducer, which has a sensitivity that is better than $0.1 \mathrm{~mm}$. The transducer was connected to a signal and data acquisition unit. The shrinkage-strain deflection is defined by the following equation:

$$
\mathrm{PS}=\frac{100\left(\mathrm{~L}_{0}-\mathrm{L}_{\mathrm{t}}\right)}{\mathrm{L}_{0}}
$$

where $\mathrm{L}_{0}$ is the height of the unpolymerized specimen $(1.24 \mathrm{~mm})$, and $\mathrm{L}_{t}$ is thickness of the polymerized specimen at the end of the polymerization process.

\subsection{Statistical Analysis}

The statistical analysis was performed using IBM SPSS Statistics 20 Software (Armonk, NY, USA). The data were evaluated to check for a normal distribution and homogeneity in variance. Analysis of variance was used to evaluate the effect of the experimental variables (radiant exposure and material) on the degree of conversion, flexural strength, elastic modulus, water sorption, water solubility, and polymerization shrinkage. The level of significance was set at $\mathrm{p}<0.05$.

\section{Results}

Figures 1-3 show the flexural properties, polymerization shrinkage, water sorption, solubility, and degree of conversion for the dental resin composites and the three different light exposure protocols. 


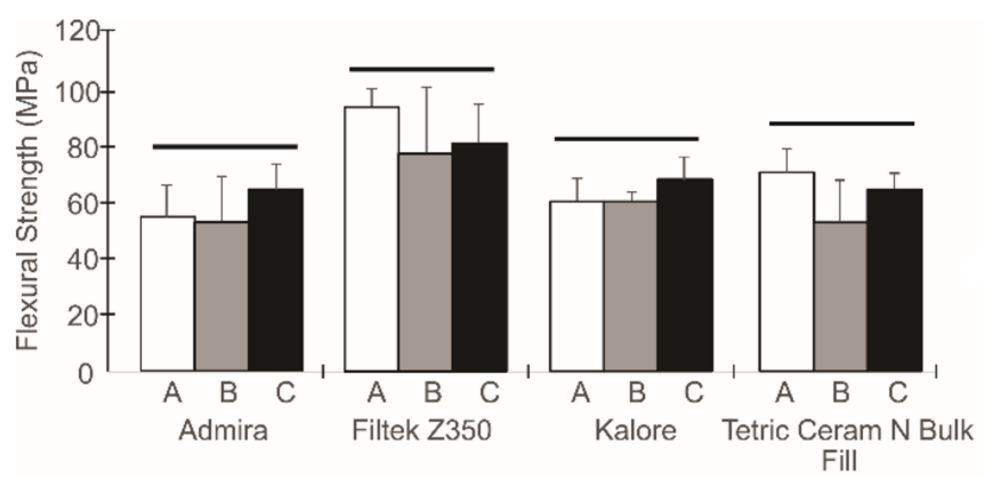

(a)

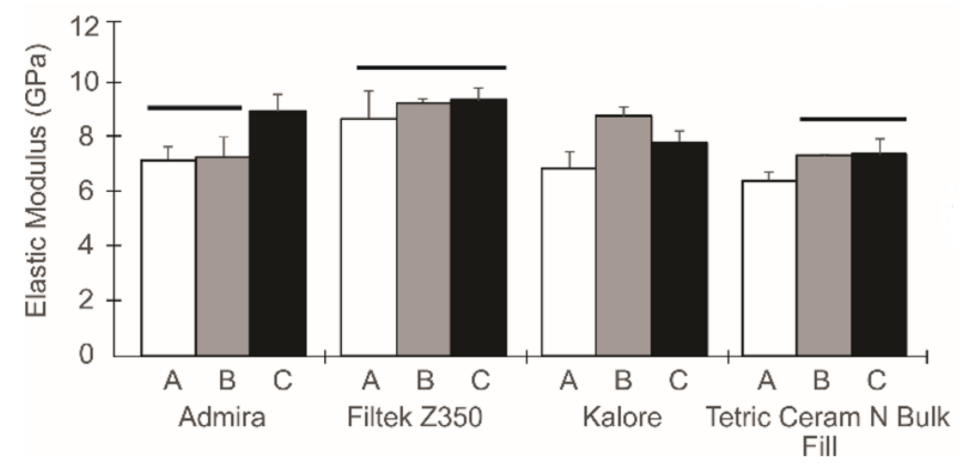

(b)

Figure 1. The flexural strength (a) and the elastic modulus (b) from different curing protocols. The columns under the same horizontal line are not statistically different.

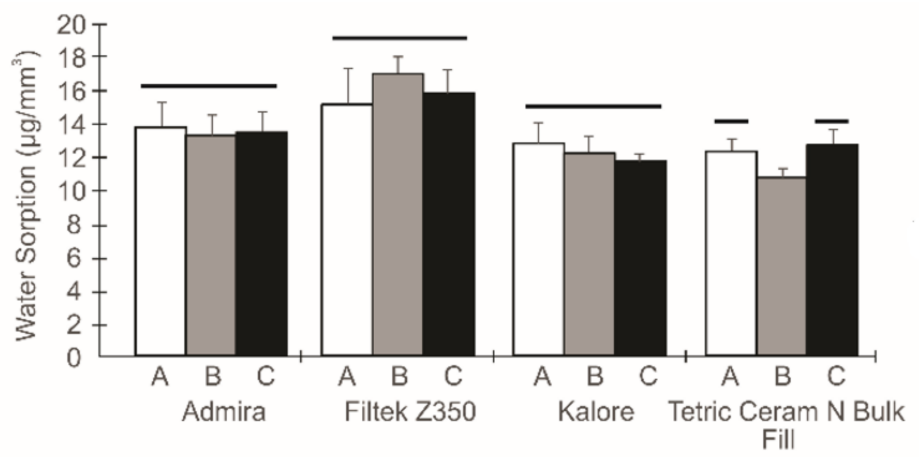

(a)

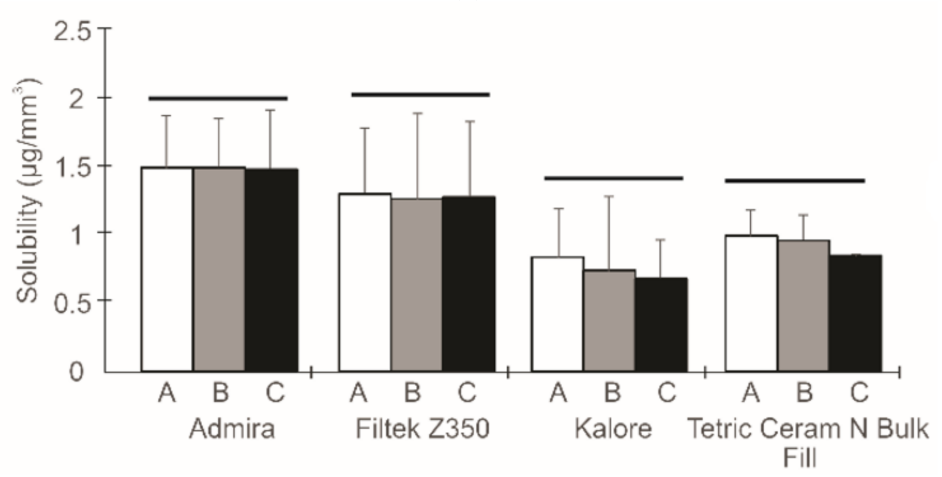

(b)

Figure 2. The water sorption (a) and the solubility (b) from different curing protocols. The columns under the same horizontal line are not statistically different. 


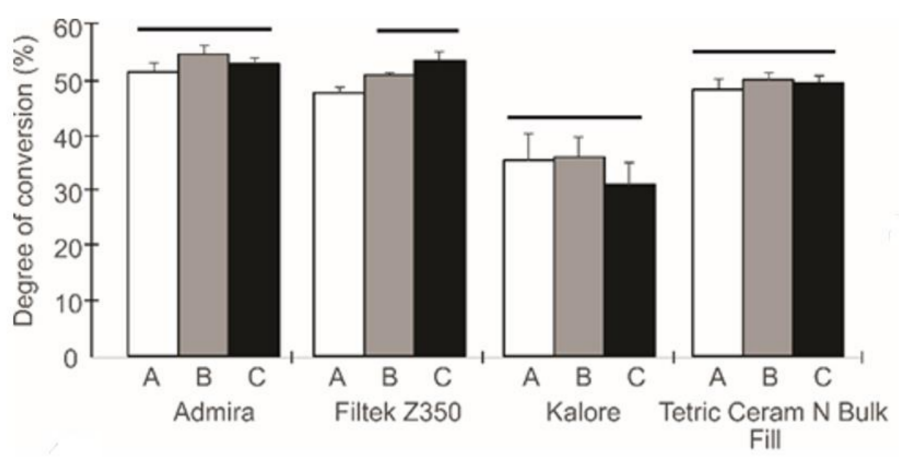

(a)

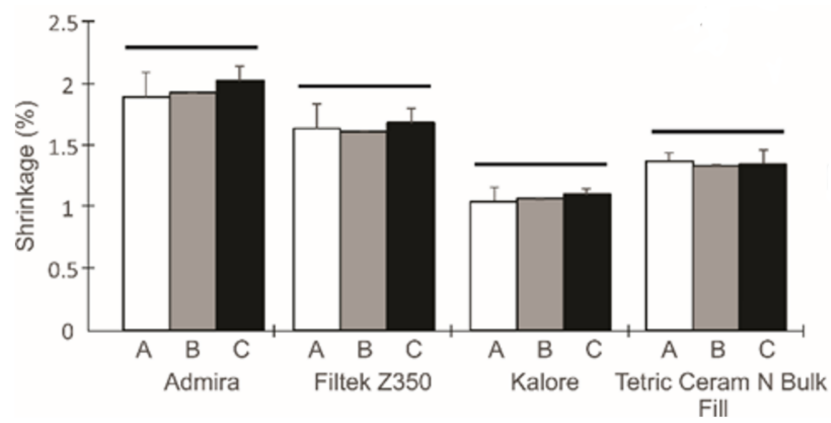

(b)

Figure 3. The degree of conversion (a) and the polymerization shrinkage (b) from different curing protocols. The columns under the same horizontal line are not statistically different.

To analyze the effect of the radiant exposure and the applicability of the exposure reciprocity law, an independent one-way ANOVA analysis was performed after pooling the data for each composite. For the Admira ${ }^{\circledR}$ composite, statistically significant differences between the light exposure protocols were observed for the elastic modulus ( $\mathrm{p}<0.001$ ), and a higher elastic modulus was achieved when a higher radiant exposure was used; this was also observed for the Kalore ${ }^{\mathrm{TM}}$ composite. For the Filtek ${ }^{\mathrm{TM}}$ Z350XT composite, differences were only observed for the degree of conversion variable $(p<0.001)$. In this case, a higher radiant exposure allowed us to obtain higher degree of conversion values. The Tetric ${ }^{\circledR} \mathrm{N}$-Ceram Bulk Fill analysis showed statistically significant differences for the elastic modulus and the water sorption $(\mathrm{p}<0.001)$; specimens that had been exposed to radiant exposures of $10 \mathrm{~J} / \mathrm{cm}^{2}$ showed higher values.

The preliminary results showed that most of the materials are governed by the exposure reciprocity law. Considering that all composites that were analyzed in this study have identical clinical indications, a one-way ANOVA analysis of the pooled data for each composite was conducted (Table 2). According to this second analysis, the Filtek ${ }^{\mathrm{TM}}$ Z350XT composite showed the highest flexural strength, elastic modulus, and water sorption values $(\mathrm{p}<0.001)$, while the Kalore ${ }^{\mathrm{TM}}$ composite showed the lowest solubility, degree of conversion, and shrinkage $(\mathrm{p}<0.001)$.

Table 2. The pooled properties of the evaluated resin-based composites.

\begin{tabular}{ccccccc}
\hline Material & $\begin{array}{c}\text { Flexural Strength } \\
(\mathbf{M P a})\end{array}$ & $\begin{array}{c}\text { Elastic } \\
\text { Modulus } \mathbf{( G P a )}\end{array}$ & $\begin{array}{c}\text { Water Sorption } \\
\left(\boldsymbol{\mu} / \mathbf{m m}^{\mathbf{3}}\right)\end{array}$ & $\begin{array}{c}\text { Solubility } \\
\left(\boldsymbol{\mu} / \mathbf{m m}^{\mathbf{3}}\right)\end{array}$ & $\begin{array}{c}\text { Degree of } \\
\text { Conversion }(\mathbf{\%})\end{array}$ & $\begin{array}{c}\text { Shrinkage } \\
(\mathbf{\%})\end{array}$ \\
\hline Filtek $^{\mathrm{TM}}$ Z350XT & $80.52(15.88) \mathrm{a}$ & $9.13(0.66) \mathrm{a}$ & $15.93(1.70) \mathrm{a}$ & $1.00(0.60) \mathrm{ab}$ & $50.96(2.77) \mathrm{ab}$ & $1.66(0.15) \mathrm{b}$ \\
$\quad$ Kalore $^{\mathrm{TM}}$ & $59.63(10.13) \mathrm{b}$ & $7.85(0.89) \mathrm{b}$ & $12.30(1.01) \mathrm{bc}$ & $0.74(0.36) \mathrm{b}$ & $33.72(4.18) \mathrm{c}$ & $1.07(0.08) \mathrm{d}$ \\
Tetric $^{\circledR}$ N-Ceram & $60.37(11.05) \mathrm{b}$ & $7.05(0.60) \mathrm{b}$ & $11.85(1.08) \mathrm{c}$ & $0.96(0.26) \mathrm{ab}$ & $49.50(1.53) \mathrm{b}$ & $1.36(0.08) \mathrm{c}$ \\
Bulk Fill $_{\text {Admira }}{ }^{\circledR}$ & $54.17(14.20) \mathrm{b}$ & $7.76(1.11) \mathrm{b}$ & $13.49(1.22) \mathrm{b}$ & $1.39(0.47) \mathrm{a}$ & $53.36(1.79) \mathrm{a}$ & $1.96(0.15) \mathrm{a}$ \\
\hline
\end{tabular}

The common corresponding letters $(\mathrm{a}-\mathrm{c})$ in a given column indicate that there are no significant differences. 


\section{Discussion}

According to the results, the exposure reciprocity law was upheld in the composites for almost all of the evaluated properties. In almost all cases, no relationship was observed between the radiant exposure and the analyzed chemical and physico-mechanical properties. Therefore, the null hypothesis of this study can be partially accepted.

Our results are consistent with previous works in which the exposure reciprocity law was found to be upheld for some properties $[8,14,19]$. In the photopolymerization process, the irradiance and light-curing time are two important factors that have an impact on the number of photons that are delivered to a specimen [20]. It has been accepted that the reciprocity law holds for most photochemical processes at reasonable light intensities [21], while at higher irradiance levels this reciprocity does not exist [19]. In this study, two levels of irradiance $\left(400\right.$ and $\left.1000 \mathrm{~mW} / \mathrm{cm}^{2}\right)$ have been used, and these levels of light intensity were not found to have any significant effect on the evaluated properties. It seems that the combinations of different irradiance and time protocols that have been used were not enough to induce a decrease or an increase in the number of radical growth centers during the early stages of polymerization, which could lead to differences in the material properties [4]. Consequently, the similarity in flexural strength, water sorption, solubility, and polymerization shrinkage among different curing protocols can be explained by the fact that the same degree of conversion was achieved in all cases. The degree of conversion is considered to be a very important material feature, and it is strongly correlated to some other material characteristics, including flexural strength and elastic modulus [22], polymerization shrinkage [23], and water sorption and solubility [24].

Among all the evaluated properties, the elastic modulus increased when higher levels of radiant exposure were delivered to the composite materials. During the photopolymerization of the dental composites, the degree of conversion and the crosslinking density increase rapidly, resulting in a rapid increase of the system's viscosity that reaches a change of state called gelation, in which the polymer matrix becomes rigid [25]. In this phase, the development of the elastic modulus is the basis for the formation of shrinkage strains and stresses because the polymer shrinkage is directly transferred to the tooth structure [26]. It has been accepted that the method by which light energy is delivered to the material is capable of delaying the gelation of a composite, and therefore several methods of light modulation have been proposed with the objective of minimizing the stress that is generated by the volumetric shrinkage. In this study, the group with a radiant exposure of $5 \mathrm{~J} / \mathrm{cm}^{2}$ presented lower values of the elastic modulus, which indicates that lower rates of conversion would allow for a better flow of the materials before they transition into the so-called gel state, which can lead to decreased contraction stresses while maintaining the other mechanical properties. Also, it is worth mentioning that the materials' acquisition of the gel phase at early stages could be detrimental to the materials' properties, since, once the materials are in the gel phase, the diffusion of free radicals through the material could be affected.

Interestingly, the Tetric ${ }^{\circledR}$ N-Ceram Bulk Fill in Group B had the lowest values of water sorption. Although the values could not be correlated with the degree of conversion, it should be emphasized that the lower values achieved demonstrated a more cross-linked polymeric network, and more resistance to hydrolytic degradation is expected [24]. Since bulk-fill-type materials possess more translucency than conventional resin-based composites, the diffusion of light through the material is higher, and, consequently, more efficiency from the polymerization material is expected [27]. This feature seems to play an important role in the stability of these materials and should be further explored.

As the different curing protocols were not found to have any significant statistical differences in most of the evaluated properties, a second analysis was performed in order to establish which composite had a better performance. The results of this analysis are depicted in Table 2 . With regard to flexural properties, the Filtek ${ }^{\mathrm{TM}} \mathrm{Z} 350$ XT composite had the highest flexural property (flexural strength and elastic modulus) values when compared with the other composites. These results are in agreement with previous studies, in which conventional composites had a higher flexural strength and a higher flexural modulus than bulk-fill composites [28], low-shrink composites [29], and ormocer-based 
composites [30]. These properties are very important features to study in dental composites in order to ensure that these materials, especially when used as posterior restorations, are not subject to the action of chewing forces that might induce permanent deformation [31]. The elastic modulus is directly related to the volume fraction of filler [32], so composites with higher filler volumes, such as the Filtek ${ }^{\mathrm{TM}}$ Z350 XT composite, are expected to be stronger than those with lower filler volumes. Also, the use of an organic matrix that is composed of monomers with stiffer backbones could probably help achieve greater flexural properties [33]. Kalore ${ }^{\mathrm{TM}}$, Admira ${ }^{\circledR}$, and Tetric ${ }^{\circledR} \mathrm{N}-\mathrm{Ceram}$ Bulk Fill presented lower flexural strength values when compared with Filtek ${ }^{\mathrm{TM}} \mathrm{Z} 350$, which suggests that these restorative materials require further study in order to fully understand the effect of their composition on their mechanical performance.

The phenomena of water sorption and solubility are important properties to study, since they may serve as precursors to a variety of chemical and physical processes, such as swelling, plasticization, softening, and hydrolysis, which can compromise the long-term mechanical properties of the materials [24]. The hygroscopic and hydrolytic characteristics of dental composites mainly depend on many factors that are related to the polymeric network structure, including the hydrophilic characteristics of the monomers it is built from [34]. The monomer TEGDMA has oxygen atoms in its ether linkages that are strongly hydrophilic and this could be the reason that Tetric ${ }^{\circledR} \mathrm{N}$-Ceram Bulk Fill achieved the lowest water sorption. This composite does not include the TEGDMA monomer in its composition, and therefore water is not attracted to the polymer matrix composite. On the other hand, the Filtek ${ }^{\mathrm{TM}} \mathrm{Z} 350 \mathrm{XT}$ composite achieved the highest values of water sorption. This behavior could be explained by the presence of the poly(ethylene glycol) dimethacrylate monomer within its polymeric matrix (Table 1), which possesses hydrophilic functional groups. In spite of the diversity in the hygroscopic behavior of the materials, it is very important to mention that, regarding water sorption and solubility, all evaluated materials exhibited values below $40 \mu \mathrm{g} / \mathrm{mm}^{3}$ and $7.5 \mu \mathrm{g} / \mathrm{mm}^{3}$, respectively, thus satisfying the conditions that are established in Specification ISO 4049.

The polymerization shrinkage in composites is directly related to the degree of conversion [35]. The values obtained in this study are in accordance with the literature for studies in which the polymerization shrinkage is evaluated through methods where the linear polymerization is calculated [28,36,37]. The Kalore ${ }^{\mathrm{TM}}$ material exhibited the lowest polymerization shrinkage and degree of conversion values. The organic matrix of this composite contains a mixture of urethane dimethacrylate, dimethacrylate co-monomers, and the DX-511 monomer. The DX-511 monomer has a molecular weight of $895 \mathrm{~g} / \mathrm{mol}$, which is twice the molecular weight of Bis-GMA or UDMA. It has been shown that the magnitude of volumetric shrinkage is mainly determined by the number of covalent bonds that are formed as well as by the size of these molecules [17]. The larger the molecules for a given material volume, the smaller the number of double bonds, and, thus, the smaller the polymerization shrinkage [38]. A reduction in the polymerization shrinkage values in Kalore ${ }^{\mathrm{TM}}$ is a desirable property, and would ensure that there is less polymerization stress, and a lower number of marginal defects and fractures, within the composite [39]. Nevertheless, lower values of double-bond conversion involve a residual monomer being trapped in the composite, which may reduce its biocompatibility and clinical serviceability [40].

\section{Conclusions}

Within the confines of this study, it can be concluded that, in most cases, the exposure reciprocity law was upheld at values of $10 \mathrm{~J} / \mathrm{cm}^{2}$ of radiant exposure. The different chemical and physico-mechanical properties that have been analyzed were not affected by the different radiant exposure values used in this study. It seems that other RBC characteristics, such as the organic matrix's composition, the type of photoinitiator, and the size and filler volume, have more of an influence on the materials' properties. 
Author Contributions: Conceptualization, C.E.C.-S. and E.Z.-C.; Formal analysis, A.R.-G. and A.L.A.-M.; Funding acquisition, E.Z.-C.; Methodology, B.P.-G., C.A.-G., and A.L.A.-M.; Project administration, E.Z.-C.; Supervision, E.Z.-C.; Writing (original draft), C.E.C.-S., B.P.-G., A.R.-G., C.A.-G., and G.G.; Writing (review \& editing), C.E.C.-S., C.A.-G., and G.G.

Funding: This research received no external funding.

Conflicts of Interest: The authors declare no conflict of interest.

\section{References}

1. Society of Cariology and Endodontology, C.S.A. Guidelines for Direct Adhesive Composite Restoration. Chin. J. Dent. Res. 2015, 18, 217-220. [CrossRef] [PubMed]

2. Devoto, W.; Saracinelli, M.; Manauta, J. Composite in everyday practice: how to choose the right material and simplify application techniques in the anterior teeth. Eur. J. Esthet. Dent. 2010, 5, 102-124. [PubMed]

3. Rueggeberg, F.A. State-of-the-art: Dental photocuring-A review. Dent. Mater. 2011, 27, 39-52. [CrossRef] [PubMed]

4. Leprince, J.G.; Palin, W.M.; Hadis, M.A.; Devaux, J.; Leloup, G. Progress in dimethacrylate-based dental composite technology and curing efficiency. Dent. Mater. 2013, 29, 139-156. [CrossRef] [PubMed]

5. Rueggeberg, F.A.; Caughman, W.F.; Curtis, J.W. Effect of light intensity and exposure duration on cure of resin composite. Oper. Dent. 1994, 19, 26-32. [PubMed]

6. Zorzin, J.; Maier, E.; Harre, S.; Fey, T.; Belli, R.; Lohbauer, U.; Petschelt, A.; Taschner, M. Bulk-fill resin composites: Polymerization properties and extended light curing. Dent. Mater. 2015, 31, 293-301. [CrossRef] [PubMed]

7. Peutzfeldt, A.; Asmussen, E. Resin composite properties and energy density of light cure. J. Dent. Res. 2005, 84, 659-662. [CrossRef] [PubMed]

8. Emami, N.; Söderholm, K.J.M. How light irradiance and curing time affect monomer conversion in light-cured resin composites. Eur. J. Oral Sci. 2003, 111, 536-542. [CrossRef] [PubMed]

9. Feng, L.; Suh, B.I. Exposure reciprocity law in photopolymerization of multi-functional acrylates and methacrylates. Macromol. Chem. Phys. 2007, 208, 295-306. [CrossRef]

10. Emami, N.; Söderholm, K.-J.M.; Berglund, L.A. Effect of light power density variations on bulk curing properties of dental composites. J. Dent. 2003, 31, 189-196. [CrossRef]

11. Vandewalle, K.S.; Ferracane, J.L.; Hilton, T.J.; Erickson, R.L.; Sakaguchi, R.L. Effect of energy density on properties and marginal integrity of posterior resin composite restorations. Dent. Mater. 2004, 20, 96-106. [CrossRef]

12. Bortolotto, T.; Dagon, C.; Krejci, I. Light polymerization during cavity filling: Effect of "exposure reciprocity law" and the resulted shrinkage forces on restoration margins. Acta Odontol. Scand. 2013, 71, 1296-1302. [CrossRef] [PubMed]

13. Asmussen, E.; Peutzfeldt, A. Polymerization contraction of resin composite vs. energy and power density of light-cure. Eur. J. Oral Sci. 2005, 113, 417-421. [CrossRef] [PubMed]

14. Selig, D.; Haenel, T.; Hausnerová, B.; Moeginger, B.; Labrie, D.; Sullivan, B.; Price, R.B.T. Examining exposure reciprocity in a resin based composite using high irradiance levels and real-time degree of conversion values. Dent. Mater. 2015, 31, 583-593. [CrossRef] [PubMed]

15. Ilie, N.; Hilton, T.J.; Heintze, S.D.; Hickel, R.; Watts, D.C.; Silikas, N.; Stansbury, J.W.; Cadenaro, M.; Ferracane, J.L. Academy of Dental Materials guidance-Resin composites: Part I-Mechanical properties. Dent. Mater. 2017, 33, 880-894. [CrossRef] [PubMed]

16. International Organization for Standarization. Available online: https://www.iso.org/standard/42898.html (accessed on 6 October 2018).

17. Alvarez-Gayosso, C.; Barceló-Santana, F.; Guerrero-Ibarra, J.; Sáez-Espínola, G.; Canseco-Martínez, M.A. Calculation of contraction rates due to shrinkage in light-cured composites. Dent. Mater. 2004, 20, 228-235. [CrossRef]

18. Ferracane, J.L.; Hilton, T.J.; Stansbury, J.W.; Watts, D.C.; Silikas, N.; Ilie, N.; Heintze, S.; Cadenaro, M.; Hickel, R. Academy of Dental Materials guidance-Resin composites: Part II-Technique sensitivity (handling, polymerization, dimensional changes). Dent. Mater. 2017, 33, 1171-1191. [CrossRef] [PubMed] 
19. Hadis, M.; Leprince, J.G.; Shortall, A.C.; Devaux, J.; Leloup, G.; Palin, W.M. High irradiance curing and anomalies of exposure reciprocity law in resin-based materials. J. Dent. 2011, 39, 549-557. [CrossRef] [PubMed]

20. Baek, C.-J.; Hyun, S.-H.; Lee, S.-K.; Seol, H.-J.; Kim, H.-I.; Kwon, Y.H. The effects of light intensity and light-curing time on the degree of polymerization of dental composite resins. Dent. Mater. J. 2008, 27, 523-533. [CrossRef] [PubMed]

21. Wydra, J.W.; Cramer, N.B.; Stansbury, J.W.; Bowman, C.N. The reciprocity law concerning light dose relationships applied to BisGMA/TEGDMA photopolymers: Theoretical analysis and experimental characterization. Dent. Mater. 2014, 30, 605-612. [CrossRef] [PubMed]

22. Palin, W.M.; Fleming, G.J.P.; Burke, F.J.T.; Marquis, P.M.; Randall, R.C. Monomer conversion versus flexure strength of a novel dental composite. J. Dent. 2003, 31, 341-351. [CrossRef]

23. Münchow, E.A.; Meereis, C.T.W.; de Oliveira da Rosa, W.L.; da Silva, A.F.; Piva, E. Polymerization shrinkage stress of resin-based dental materials: A systematic review and meta-analyses of technique protocol and photo-activation strategies. J. Mech. Behav. Biomed. Mater. 2018, 82, 77-86. [CrossRef] [PubMed]

24. Ferracane, J.L. Hygroscopic and hydrolytic effects in dental polymer networks. Dent. Mater. 2006, 22, 211-222. [CrossRef] [PubMed]

25. Cramer, N.B.; Stansbury, J.W.; Bowman, C.N. Recent Advances and Developments in Composite Dental Restorative Materials. J. Dent. Res. 2011, 90, 402-416. [CrossRef] [PubMed]

26. Sakaguchi, R.L.; Ferracane, J.L. Effect of light power density on development of elastic modulus of a model light-activated composite during polymerization. J. Esthet. Restor. Dent. 2001, 13, 121-130. [CrossRef] [PubMed]

27. Reis, A.F.; Vestphal, M.; do Amaral, R.C.; Rodrigues, J.A.; Roulet, J.-F.; Roscoe, M.G. Efficiency of polymerization of bulk-fill composite resins: A systematic review. Braz. Oral Res. 2017, 31, e59. [CrossRef] [PubMed]

28. Jung, J.H.; Park, S.H. Comparison of Polymerization Shrinkage, Physical Properties, and Marginal Adaptation of Flowable and Restorative Bulk Fill Resin-Based Composites. Oper. Dent. 2017, 42, 375-386. [CrossRef] [PubMed]

29. Goracci, C.; Cadenaro, M.; Fontanive, L.; Giangrosso, G.; Juloski, J.; Vichi, A.; Ferrari, M. Polymerization efficiency and flexural strength of low-stress restorative composites. Dent. Mater. 2014, 30, 688-694. [CrossRef] [PubMed]

30. Thomaidis, S.; Kakaboura, A.; Mueller, W.D.; Zinelis, S. Mechanical properties of contemporary composite resins and their interrelations. Dent. Mater. 2013, 29, e132-e141. [CrossRef] [PubMed]

31. Wang, L.; D'Alpino, P.H.P.; Lopes, L.G.; Pereira, J.C. Mechanical properties of dental restorative materials: relative contribution of laboratory tests. J. Appl. Oral Sci. 2003, 11, 162-167. [CrossRef] [PubMed]

32. Randolph, L.D.; Palin, W.M.; Leloup, G.; Leprince, J.G. Filler characteristics of modern dental resin composites and their influence on physico-mechanical properties. Dent. Mater. 2016, 32, 1586-1599. [CrossRef] [PubMed]

33. Azad, E.; Atai, M.; Zandi, M.; Shokrollahi, P.; Solhi, L. Structure-properties relationships in dental adhesives: Effect of initiator, matrix monomer structure, and nano-filler incorporation. Dent. Mater. 2018, 34, 1263-1270. [CrossRef] [PubMed]

34. Malacarne, J.; Carvalho, R.M.; de Goes, M.F.; Svizero, N.; Pashley, D.H.; Tay, F.R.; Yiu, C.K.; de Oliveira Carrilho, M.R. Water sorption/solubility of dental adhesive resins. Dent. Mater. 2006, 22, 973-980. [CrossRef] [PubMed]

35. Gonçalves, F.; Boaro, L.C.C.; Miyazaki, C.L.; Kawano, Y.; Braga, R.R. Influence of polymeric matrix on the physical and chemical properties of experimental composites. Braz. Oral Res. 2015, 29, 1-7. [CrossRef] [PubMed]

36. Han, S.H.; Sadr, A.; Tagami, J.; Park, S.H. Internal adaptation of resin composites at two configurations: Influence of polymerization shrinkage and stress. Dent. Mater. 2016, 32, 1085-1094. [CrossRef] [PubMed]

37. Jang, J.-H.; Park, S.-H.; Hwang, I.-N. Polymerization Shrinkage and Depth of Cure of Bulk-Fill Resin Composites and Highly Filled Flowable Resin. Oper. Dent. 2015, 40, 172-180. [CrossRef] [PubMed]

38. Soares, C.J.; Faria-e-Silva, A.L.; de Paula Rodrigues, M.; Vilela, A.B.F.; Pfeifer, C.S.; Tantbirojn, D.; Versluis, A. Polymerization shrinkage stress of composite resins and resin cements-What do we need to know? Braz. Oral Res. 2017, 31. [CrossRef] [PubMed] 
39. Narene, A.V.K.; Veniashok, B.; Subbiya, A.; Vivekanandhan, P.; Sukumaran, V.G. Polymerisation shrinkage in resin composites-A review. Middle East J. Sci. Res. 2014, 21, 107-112. [CrossRef]

40. Ausiello, P.; Cassese, A.; Miele, C.; Beguinot, F.; Garcia-Godoy, F.; Di Jeso, B.; Ulianich, L. Cytotoxicity of dental resin composites: An in vitro evaluation. J. Appl. Toxicol. 2013, 33, 451-457. [CrossRef] [PubMed] 